\title{
The First5 Concept
}

\section{INTRODUCTION}

During specialty training, Associates in Training (AiTs) are well supported. They have regular contact with their trainer, peer support at the GP specialty-training programme and a job, often guaranteed for the 3 years running up to obtaining a Certificate of Completion of Training (CCT). All this changes the day after finishing training when the weekly specialty training programme meetings stop and the trainer is no longer in the next room. New GPs find themselves in the ever-changing landscape of modern general practice. ${ }^{1}$ New GPs have so many options open to them at this point and may be salaried, locums, or partners and work in out-ofhours or urgent care centres, undertake academia, or become a forces doctor. All these young doctors often share a common sense of 'falling off a cliff' at the end of training. The RCGP has established a special group for newly qualified GPs to help support and develop their clinical and professional skills during the first crucial 5 years as independent practitioners.

\section{THE FIRST5 CONCEPT}

The First5 concept came from the RCGP AiT Committee, when in 2008-9 the committee recognised a gap in support for it's Members. The First5 concept was developed to help support new GPs from completion of training to the first point of revalidation at the 5-year mark. This essay explains the origin of the concept and the five pillars which we envisage being crucial to the First5 concept.

\section{A CHANGING LANDSCAPE}

General practice is a career, which offers a great variety and diversity of possible career pathways, with many GPs choosing to pursue special interests or portfolio careers. The traditional model of working full time as a practice partner, which used to be the norm for most GPs is no longer the case. ${ }^{1}$ Politically there have been many changes over recent years and with this has come the threat of privatisation of the health service ${ }^{2}$ and the once guaranteed partnership seems increasingly elusive. ${ }^{1}$
There is a shift from a predominantly male to female workforce and both sexes increasingly want to work less than full time to achieve a favourable work-life balance. ${ }^{3}$ In the past, higher professional education (HPE) provided a funding opportunity for newly qualified GPs to undertake further training, this provision has largely disappeared. ${ }^{4}$ The landscape which trainees saw when deciding to enter general practice may be very different to that which they find on completing their training.

\section{A NEW ERA}

The introduction of the new Membership of the Royal College of General Practitioners examination (nMRCGP) in 2007 marked a new era in general practice training. For the first time the College became responsible for providing a licensing examination required by all aspiring GPs in the UK. This also coincided with the publication of the first comprehensive curriculum by the RCGP. The College encouraged trainees to become Associates-in-Training (AiT) and there are now over 9000 associate members making up nearly a quarter of the total membership. AiTs have regular contact with the RCGP to facilitate examinations, as well as support with the AiT e-newsletter, regular copies of the RCGP trainee journal InnovAiT as well as the monthly RCGP News and this publication, the British Journal of General Practice. The College is well placed to continue this support through the early years of the GP career.

\section{REVALIDATION}

The General Medical Council will require all practitioners to undertake revalidation every 5 years. ${ }^{5}$ New GPs may initially find themselves locuming or working in shortterm salaried positions and will need additional support to ensure they are able to collect adequate supporting information for revalidation. They will already be familiar with e-portfolios, reflective learning and workplace based assessment from their time as a trainee so these skills will be beneficial. However, as many new GPs will be working as peripatetic locums or as salaried GPs in more than one practice the opportunity to collect information may be more challenging and the RCGP are developing guidance and alternative methods more suitable for different working environments. The First5 programme will provide support and guidance as revalidation develops.

\section{EXTENDED GP TRAINING}

General practice is the cornerstone of the NHS and highly skilled generalists are vital to serve the complex needs of our aging population. At the end of training, GPs are competent to practise independently, but are often not confident in some areas of practice. There is evidence that extending GP training can help to address these outstanding learning needs ${ }^{6}$ and the GP curriculum was originally designed to be delivered over 5 years. Professor Sir John Tooke, in his report 'Aspiring to Excellence' which followed the controversial introduction of the Medical Training Application System, suggested that training in general practice should be increased to 5 years. ${ }^{7}$ However, the case for extension of GP training was rejected by HM Treasury earlier this year. There is therefore a need to provide support for new GPs in their first few years after training to ensure they grow in confidence and expertise.

\section{THE FIVE PILLARS OF FIRST5}

The concept of First5 can be considered in terms of five pillars, which summarise what could be achieved:

1.Connecting with the College Promoting a sense of belonging and appropriate representation for the First5 cohort within the College.

The RCGP has a reputation for promoting high quality standards in general practice and as the largest medical royal college has considerable influence at home and abroad. The power and influence of the College however depends on both the number and engagement of its members. It 
is in the best interests of new GPs to have a college that has a strong voice to maintain standards within general practice. The post-nominal 'MRCGP' signifies a high quality of general practice training, which is recognised by employers and indeed many patients. However in order for the College to adequately represent the First5 cohort there must be a move towards greater representation of those at the start of their careers within RCGP. There is a risk that the voice of the First5 cohort will not be heard unless more proportionate representation is achieved.

\section{Facilitating networks - Encouraging} peer support and mentoring through the development of local networks.

GPs who have recently completed training can feel isolated and may initially feel under-confident in their new role outside of the supportive training environment. Understanding that others may have similar feelings and worries can be reassuring and establishing a small group which meets regularly can be a good way to obtain peer support and also undertake continuing professional development. This method of working may benefit further from having regular contact with a senior GP to act as a mentor to either the whole group or individuals within the group. ${ }^{8}$

\section{Supporting revalidation - Offering} support through revalidation for those in the first 5 years post-CCT.

New GPs are taking on varied roles in the profession, although are more likely to be undertaking locum work or a short-term salaried position than older colleagues. Irrespective of where newly qualified GPs work they will want to ensure that they meet the requirements to be revalidated after 5 years. Good Medical Practice for General Practitioners describes the standards expected of GPs in the UK and forms the basis of the requirements for revalidation, ${ }^{9}$ but the RCGP document Revalidation Criteria, Standards and Evidence ${ }^{10}$ acknowledges that some groups of GPs may find a conventional revalidation folder difficult to generate. There are concerns that GPs who do not have regular work in one practice will find it harder to gather some items, such as multi-source feedback from colleagues, patient surveys, significant event analyses, and audits of care. A disproportionate amount of First5 GPs are likely to fall into this category. There are revalidation pilots underway to address these issues and we envisage First5 GPs being supported as part of the wider College revalidation programme.

\section{Career mentorship - Highlighting the} opportunities a career in general practice offers and helping new GPs get the most out of being a GP.

Careers in general practice are diverse and offer a huge range of opportunities. New GPs may choose to be a salaried GP, locum, become a partner or may do out-ofhours work as a main source of income. Practices can differ in terms of location, management structure, and patient population. Some GPs choose to develop special interests and may become practice lead in one disease area or become accredited as a GP with a special interest. There are also opportunities in management, education, and research. The First5 concept could support new GPs through the process of finding out what that 'dream job' might be by providing guidance and highlighting opportunities. International links could also be developed to allow experience of working in family medicine in different healthcare systems.

\section{Continuing professional development} (CPD) - Identifying areas of CPD which members in the first 5 years feel are not well provided and developing materials that will address their learning needs.

CPD is an essential part of general practice, which ensures GPs improve their knowledge and skills throughout a professional lifetime. CPD activity is currently reviewed during the annual appraisal and will form an essential part of revalidation. Throughout GP training, AiTs are encouraged to develop a personal development plan and be reflective in their learning style. At the end of training, AiTs should be competent in the main areas of practice but may not feel confident in more complex areas. This should be taken into account when considering the CPD needs of First5, which may differ from those of the entire membership. Provision of tailored CPD to meet the specific needs of First5 could be beneficial while still being useful to GPs at all stages of their career. Topics such as advanced consultation skills; and practice management, leadership and commissioning are examples of CPD modules ideal for First5. The first 5 years after training is the time when support in developing confidence and skills in becoming an independent practitioner is needed the most.

\section{SUMMARY}

The concept of First5 recognises the challenges faced by GPs at the end of training and comprises five pillars, which could help to support new GPs through the first 5 years of independent practice. The world of general practice is constantly changing and it is important that new GPs can be supported to develop the confidence and skills required to meet the demands of the new healthcare world.

\section{Clare Taylor, James Parsons, Nigel Sparrow and Clare Gerada}

\section{REFERENCES}

1. Gerada C. Changing partnerships. Royal College of General Practitioners, March 2009.

http://www.rcgp.org.uk/pdf/corp_Changing_Partnership s.pdf (accessed 26 Nov 2010).

2. Pollock A. NHS Plc: The privatisation of our health care. London: Verso, 2005

3. Deech B. Women doctors: making a difference. London Department of Health, 2009.

http://www.dh.gov.uk/prod_consum_dh/groups/dh_digi talassets/@dh/@en/@ps/documents/digitalasset/dh_1153 74.pdf (accessed 3 Dec 2010).

4. Howard J, Pitts J. The provision of higher professional education to general practitioners in England. A review of the HPE scheme for GPs in England. Medical Teacher 2005; (27): 481-483.

5. Royal College of General Practitioners. RCGP Guide to the Revalidation of General Practitioners version 4.0. London: RCGP, 2010.

http://www.rcgp.org.uk/PDF/PDS_Guide_to_Revalidati on_for_GPs.pdf (accessed 26 Nov 2010).

6. O'Shea EB. Extension of training for general practice: a review of the evidence. Educ for Prim Care 2009; 20: 15-20.

7. Tooke J. Aspiring to excellence. Final Report of the Independent Inquiry into Modernising Medical Careers. London: Department of Health, 2007.

http://www.mmcinquiry.org.uk/Final_8_Jan_08_MMC all.pdf (accessed 3 Dec 2010).

8. Standing Committee on Postgraduate Medical and Dental Education (SCOPME). Supporting doctors and dentists at work. An enquiry into mentoring. SCOPME: London, 1998.

9. Royal College of General Practitioners. Good Medical Practice for General Practitioners. London: RCGP, 2008. http://www.rcgp.org.uk/PDF/GMP_web.pdf (accessed 26 Nov 2010).

10. Royal College of General Practitioners. Revalidation criteria, standards and evidence: outcome of consultation with stakeholders and the profession. London: RCGP, 2008.

DOI: 10.3399/bjgp11X549135 